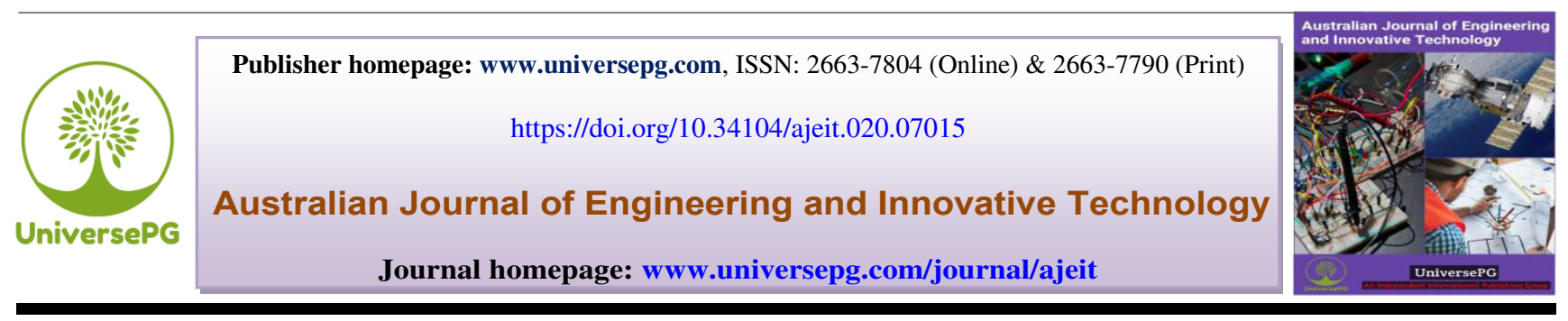

\title{
Impact of Weather on Crops in Few Northern Parts of Bangladesh: HCI and Machine Learning Based Approach
}

\author{
Md. Toukir Ahmed ${ }^{1 *}$, Md. Niaz Imtiaz ${ }^{1}$, and Nurun Sakiba Mitu ${ }^{1}$ \\ ${ }^{1}$ Department of Computer Science and Engineering, Pabna University of Science and Technology, Pabna, Bangladesh \\ *Correspondence: toukirahmedreal@gmail.com
}

\begin{abstract}
As Bangladesh is an agricultural country, the economy as well as food security of this country mostly depends on production level of different crops over the year. Therefore, there exists immense pressure on exaggerated crop production due to fast growth of population. But, average production level is being hampered by bad nature of weather. We have conducted a survey on near about 100 farmers of two northern districts of Bangladesh: Pabna and Rajshahi and assessed impact of rough nature on production. According to farmers and agriculturalists, it is noticed that rough weather causes about $30 \%$ to $70 \%$ production shortage than expectation with all other factors remaining constant. In this study, we have adopted Human computer interaction (HCI) based approach (Soft System Methodology-SSM) to this aspect for efficacious collaboration with root level farmers and agricultural trainers providing ease for understanding weather related issues on production of crops. Finally, some machine learning algorithms were also implemented on the obtained dataset to accurately classify the range of production level of rice and a comparison is made among the algorithms based on performance metrics. Moreover, an android based application is created to depict the summary of the study.
\end{abstract}

Keywords: HCI, Machine learning, Performance metrics, SSM, Weather, Impact, and Northern parts.

\section{INTRODUCTION:}

Bangladesh is an agricultural country. The economy of this country still largely depends on production level of different crops over the year. So, sound production is concerning issue here, but production of crops decreases due to some unusual negative behavior of the weather. Climate variability and vulnerabilities are among growing concerns worldwide (Ruksana Haque Rimi, 2009). The climate of Bangladesh is changing and it is becoming more unpredictable every year (Ruksana Haque Rimi, 2009). The world population might reach approximately 10.6 billion people by 2050 (Pereda, 2018). From this expected population growth, food demand might become double with respect to present day's consumption (Pereda, 2018). Consequently, the agricultural sector will be challenged to ensure future food security (Pereda, 2018). Our book shows the impact of weather on crops in case of two districts in Bangladesh (Pabna and Rajshahi). The nature of weather in these regions is classified as (1) Heavy Rainfall (2) High Temperature, (3) Heavy Cold by the definition of officers.

Some scientists outline climate because the average weather for a selected region and period sometimes condemned 30 years (Jayanta Kumar Basak, 2013). It's a very median pattern of weather for a selected region. When Scientists state climate they were watching averages of the weather that occur over an extended amount in a very explicit place (Bagchi et al., 2019).

Actually, the difference between weather and climate is a measure of time. Weather is what conditions of 
the atmosphere are over a short period of time, and climate is how the atmosphere "behaves" over comparatively long periods of time (Deepak K. Ray Navin Ramankutty, 2012). We have a tendency to hear about weather and climate all of the time. Most people check the local weather forecast to plan our days. And change in climate is actually a "hot" topic within the news (Islam et al., 2019).

In recent years, several extreme weather disasters have partially or completely damaged regional crop production (Md. Ruhul Amin, 2015). As, prolonged regional accounts of the telltale effects of noxious weather catastrophes are still in existence, the global scale side-effects of droughts, floods and acute temperature on crop cultivation and production are still to be quantified (Alex C. Ruane, 2013). Here authors quantified, to their utmost knowledge, national cereal manufacture losses across the globe indicated from reported acute weather disasters during 1964-2007 (Corey Lesk, 2016).

Some researchers also show that droughts and acute heat perniciously abridged national cereal production by $9-10 \%$, whereas their analysis could not indicate an effect from floods and extreme cold in the national data (Fraser, Crops and climate change: progress, trends, and challenges in simulating impacts and informing adaptation, 2009). Analyzing the elemental processes, they later found that, production losses due to droughts were associated with devaluation in both cultivated area and yields, whereas acute heat mainly depreciated cereal yields. Furthermore, the results highlight $\sim 7 \%$ larger production depreciation from more recent droughts and $8-11 \%$ more in developed countries than in developing ones (Md Torikul Islam, 2017). The main necessities of the proposed work that to compare the change in weather with the production level of crops, and get the appropriate result by using various methodologies.

A good portion of our work is focused on HCI. HCI works primarily on the social problems of the general public and produces a report that is subsequently solved using another model (Islam and Hossain, 2019). We can create new algorithm or implement various algorithm with the data. We selected one of the common problems at the present situation. There were two districts in Bangladesh visited by us. We

UniversePG I www.universepg.com have talked face to face with many farmers who are directly related with farming. We created different category questions for them and asked them. Many times, we got our desired answer, never again. We were trying to understand the problems of the crops as a result of changing weather. Later we have talked to the officers of various levels and learned the solution of the problem. There were different questions for the officers too. And we did it all according to the SSM methodology of HCI. From the survey report, we found that by using good seeds which supplied from agricultural office, farmers get more production than before. Questions were asked to the farmers and officers on impact of bad weather on Bangladeshi crops.

We have made a mobile app using Android application which shows the data and suggestion as table or graphically or as text. Our research paper extends the work of HCI to the Machine Learning. We used Weka and classified various model which shows different accuracy (Islam et al., 2020). And finally, we compared different algorithms to find out the best performing algorithm.

The remaining part of the paper is organized as follows: First we start discussing about state of the art approaches of relevant works, next we discuss about experimental methods used in the study. Then we proceed by explaining the design of our proposal and the experiments carried out in the result section. Lastly, we cite the relevant conclusions.

\section{CONCEPTUAL PERSPECTIVE AND LITER- ATURE REVIEW:}

In its earliest, many experiments and models were being carried out for measuring the negative and positive impact of weather on different kinds of crops, in Bangladesh and other countries also. And they created a lot of algorithms for getting accurate result. The global demand for agricultural crops is expected to roughly double by 2050 , driven by increases in population (Deepak K. Ray, 2012). Clearly, these recent growths in global crop manufacture lags behind of the quotidian demands, leaving us with a significant question: which crops and which geographic places subsume the best hope of meeting expected demands, and where developments are urgently needed? 
The models are so important to show the importance of weather changing in Bangladesh and it was helpful to promote research on weather changing in Bangladesh by using different kinds of models, and here we used several methodology from book namely Human Computer Interaction, written by Alan Dix (Dix, 2003). He described a lot in his book about HCI. The model which was described in the book could be used if there was lack of data to fit the modeling data. These assumptions of model were worked well enough (though never perfectly) under the infrastructures, based on users, and agricultural conditions of the Bangladesh. Some paper concluded farmers do not have accurate awareness about how to cultivate systematically. They created awareness about the crop insurance was primarily on the basis of age and education level followed by how much land they holding and experience in the farming.

\section{METHODOLOGY:}

Human-computer interaction (HCI) researches are concerned with design and usage of computer technology, focused largely on the interfaces between people (users) and computers. Researchers in the field of HCI both peruse the different styles in which humans interact with computers and design technologies that let humans collaborate with computers in unique ways (Dix, 2003). HCI puts more weight on users working specifically with computers, compare to other kinds of machines or designed artifacts (Dix, 2003).There is also a focus in $\mathrm{HCI}$ on how to implement the computer software and hardware mechanisms to support human-computer interaction (Dix, 2003).

\section{A. CUSTOM methodology}

A socio-technical methodology designed to be practical to use in small organizations, is known is a CUSTOM methodology (Andrew Faulring, 2012). It is supported the User Skills and Task Match (USTM) approach, developed to allow design teams to understand and fully document user requirements. CUSTOM focuses mainly on establishing stakeholder requirements: all stakeholders are considered, not just the end-users. It is applied at the initial stage of design when a product chance has been identified, so the emphasis is on capturing requirements.
It is a forms-based methodology, providing a set of inquiries to apply at each of its stages. It has six key stages to carry out in a CUSTOM analysis:

$>$ Describe the organizational context, including with primary goals, physical characteristics, political and economic background.

$>$ Identify and describe stakeholders: All stakeholders are named, categorized (as primary, secondary, tertiary or facilitating) and described with regard to personal issues, played role in the organization and their job.

$>$ Identify and describe work-groups: A workgroup is any group of people who work together on a task, whether formally constituted or not. Again, work-groups are prescribed in terms of played role in the organization.

$>$ Identify and describe task-object pairs: These are the tasks that must be accomplished, deployed with the objects that are used to perform them or to which they are applied from.

$>$ Identify stakeholder needs: Stages 2-4 are described in perspective of both the current system and the proposed system. Stakeholder needs are identified by considering the differences between the two.

$>$ Consolidate and checks stake holder requirement: Here the stakeholder needs list is checked against the criteria deployed at earlier stages.

\section{B. Soft Systems Methodology (SSM)}

The socio-technical models we have looked at focus on identifying requirements from both human and technical directions, but they assume to be proposed a technological solution (Anita Mirjamdotter, 2009). Soft systems methodology (SSM) comes from the same identical tradition but takes a view of the organization as a system of which technology and people are the key components. There is no presumption of a specific solution: the emphasis is rather on understanding the situation fully. SSM was developed by Check-land. The first stage of SSM is the recognition of the problem and initiation of analysis. This is followed by a detailed description of the problem situation: developing a rich picture. This will comprise with all the stakeholders, the day to 
day tasks they carry out and the groups they work in, the organizational structure and its processes and the issues constructed by each stakeholder.

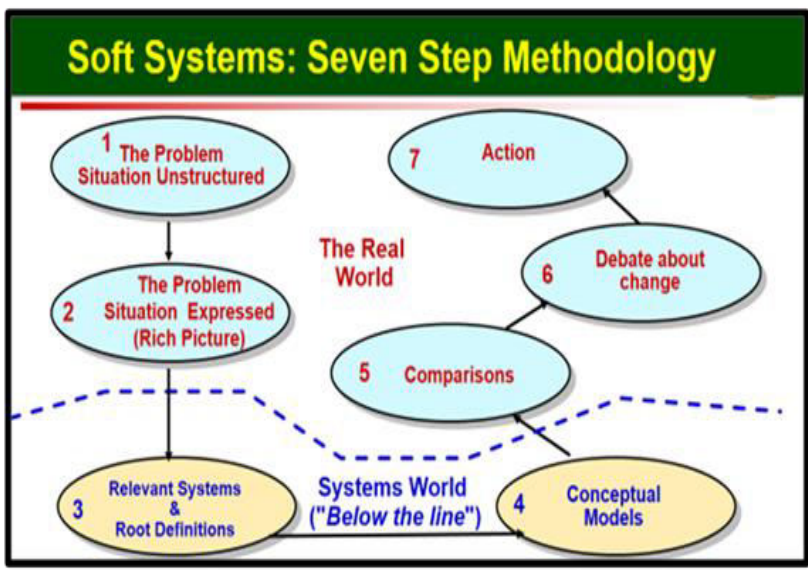

Fig 1: Seven stages of Soft System Methodology (Anita Mirjamdotter, 2009).

At the next stage in SSM we move from the real world to the systems world and attempt to generate root definitions for the system, which define the essence of what the system is about. The conceptual model defines what the system has to do to fulfill the root definitions. Next, we return to the real world with our systems descriptions and compare the actual system with the conceptual model, identifying discrepancies and thereby highlighting any necessary changes or potential problems (Akter et al,. 2019).

In the final stages, we determine which changes are necessary and beneficial to the system as a whole changes may be structural, procedural or social, for example- and decide on the actions required to effect those changes. SSM is a flexible approach, which supports detailed consideration of the design context. However, it takes practice to use effectively. There is no single right (or wrong) answer - the SSM is successful if it aids the designer's understanding of the wider system.

\section{Model Building}

We need to analyze the Naive Bayes, Sequential Minimal Optimization, j48, Multiclass classifier and Decision Table by classifying the transactional dataset.

\section{Naïve Bayes}

Naïve Bayes is a statistical classifier that assumes no dependency between attributes. Naïve Bayes algorithm uses conditional independence, means it assumes that an attribute value on a given class is UniversePG I www.universepg.com independent of the values of other attributes. One can work with the Naive Bayes model without using any Bayesian methods; this is the main advantage of Naïve Bayes (Russell, 2002).

\section{Sequential Minimal Optimization}

Sequential Minimal Optimization (SMO) is a SVM (support vector machine) driven algorithm. Perception learning algorithm is essentially doing same thing find a linear separator by adjusting weights on misclassified examples. Unlike perception, SMO has to maintain sum over examples of example weight Ames example label (Russell, 2002).

\section{J48}

It is a machine-learning based predictive model which decides the target value of a new sample based on various attribute values of the available data is $\mathrm{J} 48$ decision tree. The different attributes denoted by the internal nodes of a decision tree, the branches between the nodes tell us the possible values that these attributes can have in the experimental samples, while the terminal nodes tell us the final value of the dependent variable (Russell, 2002).

\section{Multiclass classifier}

In multiclass classification, each record belongs to more than two classes, and the algorithm's goal is to design a function which, given a new data point, will correctly classify data. Multiclass classification incorporates the number of pragmatic business problems; researchers can gain insight into with machine learning. This is just one example of a business use case for multiclass (Russell, 2002).

\section{Model Evaluation in Weka}

We implemented the proposed algorithms in WEKA (Hall, 2009). We used 10-fold cross validation method to investigate performances of algorithms. For performance measurement we used accuracy, sensitivity, specificity, precision, Recall, ROC, PRC area. We checked all these parameters to find out the better performing algorithm.

\section{RESULTS AND DISCUSSIONS}

\section{A. Data collection}

Rice production occurs on more than $80 \%$ of the agricultural land in Bangladesh (Ruane). The three 
kinds of rice seasons are: aus, aman, boro. Rice cultivation makes up nearly $95 \%$ of cereal production in Bangladesh (Ruane). Rice is threatened by floods during the pre-monsoon (aus), and monsoon (aman) season and by heat weaves and water scarcity during the dry monsoon (boro) season (Ruane). For rice producing, Bangladesh is the fourth largest country in the world.

Table 1: Data for rice in Rajshahi District.

\begin{tabular}{|l|l|l|l|l|}
\hline Year & $\begin{array}{l}\text { Rainfall } \\
(\mathbf{m m})\end{array}$ & $\begin{array}{l}\text { Temp } \\
\left({ }^{\circ} \mathrm{C}\right)\end{array}$ & $\begin{array}{l}\text { Production } \\
(\mathbf{M T})\end{array}$ & $\begin{array}{l}\text { Price } \\
(\mathbf{T k})\end{array}$ \\
\hline 2013 & 160.44 & 31 & 138.05 & 880 \\
\hline 2014 & 171.86 & 33 & 144.25 & 1100 \\
\hline 2015 & 208.37 & 32 & 150.60 & 910 \\
\hline 2016 & 170 & 33 & 155.62 & 900 \\
\hline 2017 & 191.98 & 33 & 163.15 & 750 \\
\hline
\end{tabular}

Table 2: Data for rice in Pabna District.

\begin{tabular}{|c|c|c|c|c|}
\hline Year & $\begin{array}{c}\text { Rainfall } \\
(\mathbf{m m})\end{array}$ & $\begin{array}{c}\text { Temp } \\
\left({ }^{\circ} \mathrm{C}\right)\end{array}$ & $\begin{array}{c}\text { Production } \\
(\mathbf{M T})\end{array}$ & $\begin{array}{c}\text { Price } \\
(\mathbf{T k})\end{array}$ \\
\hline 2013 & 152.17 & 31 & 270.05 & 880 \\
\hline 2014 & 116.86 & 32 & 285.05 & 1100 \\
\hline 2015 & 263.09 & 32 & 300.90 & 910 \\
\hline 2016 & 126.07 & 33 & 298 & 900 \\
\hline 2017 & 152.15 & 33 & 306.7 & 750 \\
\hline
\end{tabular}

\section{Survey on Farmers}

A farmer SM Khalilur Rahman Khalil age 55 from Kanaipara, Puthia of Rajshahi district engaged with agriculture near about 35 years, shared a lot of things from his long experience. He cultivated paddy, jute, pulse, potato in his 1 acre of land, but he has no objection about the infrastructure of our agriculture system, and moreover he always get different directions from the agricultural officers. He added most of the time production level hampered due to natural disaster rather than our resources and also pointed that technology in agriculture is enriched enough for sound production of different crops.

We have interviewed near about 40 farmers from Pabna and others 40 from Rajshahi district and them all shares their views regarding these bad consequences of weather. Among them Mahatab Hossain and Abdur Rouf said for excessive raise in temperaturesoil dried out and for lack of irrigation facilities production of cultivated crops decreases in a remarkable margin.

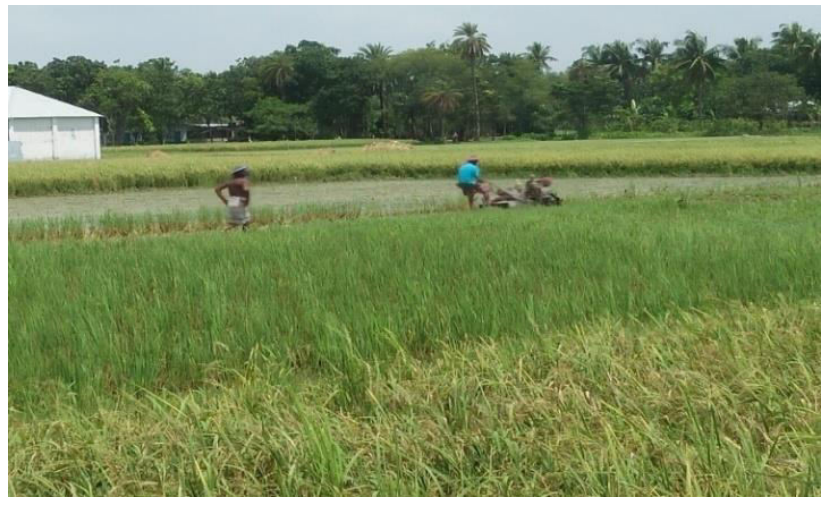

Fig 2: SM Khalilur Rahman works at his farm.

Whenever rain is necessary then it doesnot but unnecessary rains for 2-3 days happens that rotten the roots of crops and crops are attacked by different diseases, also in this way they have to face forced unwanted losses. As we know winter season is most fitted for wheat cultivation but except 2017 in all other year temperature gradually raises and coldness in winter decreases for that reason it is being tough for getting standard quality in wheat. The farmers also claim that most of the time they don't get sufficient advises from the officers and field supervisors less likely visited their farm that's why they faced a lot of problems. Moreover, the farmers who are educated and concern they said as they got quality seeds but the losses from weather impact still not discovered at standard level.

\section{Officers Suggestions}

Md Abdul Khalek (Age 60) of Uttarcak of Athghoria in Pabna district who engaged with agriculture after completing his SSC degree due to financial crisis of his family from that time about 40 years passed he nursing agriculture with his knowledge and hard work. For his dedication and contribution in agriculture he received gold medal from the honorable prime minister. Now he is working as a trainer in Krishok Math School and providing training to root level farmers. In this era of advanced science and technology he claims that by discovering different hybrid flood, drought, winter tolerant seeds it is not possible to decrease the losses happened through bad impact of weather. A sub assistant agriculture officer Md Anis from Puthia (Rajshahi) who is engaged with this profession near about 20 years said that due to filling up riversides, destruction of forest, wastage, fumes of factories has affected the 
natural environment drastically for that reason natural resources also hampered and the natural environment have to face uneven situation that causes serious effect on agriculture.

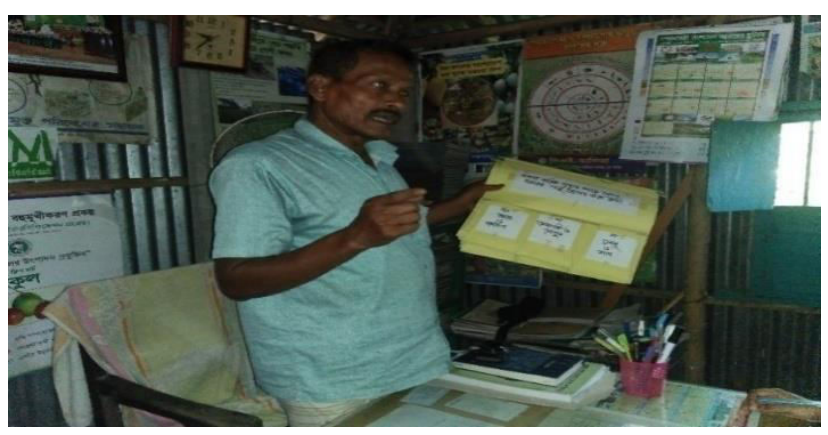

Fig 3: Md Abdul Khalek- a trainer in Krishok Math School.

After interviewing 20 officers we have come to a conclusion that some of them are suggesting for paying attention to individual personnel to step up and while other suggesting for raising awareness to government agricultural offices, and more ever few of them paying attention to environmental organization to come out for these situations. Also they suggested for some varieties of hybrid seeds. Drought Tolerant: BRRI 42 and 43, Flood Tolerant: BRRI 51 and 52, heavy cold: BRRI 36 (all for rice). For wheat: BARI 26, 27, 28, 29 and 30. Moreover planting more and more trees, avoid polythene, use of improved quality seeds, take advice from officers will be positive side to improve our agricultural condition much.

Bangladesh nuclear Research Institute is able to product paddy in 115 days instead of 120 days. It is a huge achievement. So, proper research should pay concern to tackle these situations.

\section{E. Questionnaires for Farmers}

We define a questionnaire as an instrument for collecting data, which almost involves asking a given subject to respond to a set of oral written questions. A questionnaire and survey are not the same. A survey is a method of extracting data that could collaborate a wide range of data collection methods, including questionnaire. One of the cardinal merits of it is being able to ask as many questions as desired. Of course, it benefits the vendor to stay every individual questionnaire short, since protracted form frustrating.

A questionnaire was created for the farmers including following questions:

UniversePG I www.universepg.com
Q1: What is your farm size?

Q2: What area of your farm did you use to grow rice last season?

Q3: How many paddy seedlings do you plant?

Q4: what yield did you normally get?

Q5: Was there any natural hazard(s) that affected your yield level in the last season?

Q6: If answer is yes, what was that?

Q7: If last season's yield was affected by natural hazards, what yield did you normally get?

Q8: On a five point scale below, how do you rate efficiency as a rice farmer compared to other farmer in this area?

\begin{tabular}{|l|l|l|l|l|}
\hline$*$ & $* *$ & $* * *$ & $* * * *$ & $* * * * *$ \\
\hline (Worst) & \multicolumn{3}{|c|}{ (Average) } & (Best)
\end{tabular}

\section{F. Summarization of Survey}

To summarize the survey and putting replies of the questionnaire in a tabular form, we assumed following short forms:

Yes $=1$

$\mathrm{No}=0$

Heavy Raining $=11$

Heavy Temperature $=22$

A glimpse of our tabular questionnaire is deployed in Table 3.

Table 3: Answers based on the given questionnaire (for rice).

\begin{tabular}{|c|c|c|c|c|c|c|c|c|}
\hline 昰 & 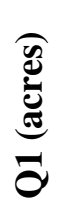 & 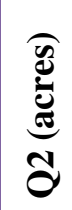 & $\ddot{\theta}$ & 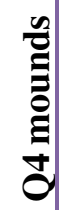 & 8 & $\widehat{\sigma}$ & 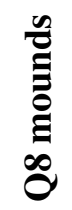 & $\hat{\theta}$ \\
\hline $\begin{array}{l}\text { Md Amir } \\
\text { Hossain }\end{array}$ & 0.5 & 0.5 & 550 & 28 & 1 & 11 & 20 & $*$ \\
\hline Md Babu & 1 & 0.5 & 600 & 30 & 1 & 11 & 32 & $* *$ \\
\hline $\begin{array}{l}\text { Md Ali } \\
\text { Hossain }\end{array}$ & 0.87 & 0.87 & 800 & 34 & 0 & 00 & 34 & $* *$ \\
\hline $\begin{array}{l}\text { Md Imran } \\
\text { Ali }\end{array}$ & 1.5 & 1 & 1000 & 60 & 1 & 11 & 58 & $* *$ \\
\hline Md Malek & 2 & 1 & 1250 & 55 & 1 & 22 & 30 & $*$ \\
\hline $\begin{array}{c}\text { Md } \\
\text { Habibur } \\
\text { Rahman }\end{array}$ & 3 & 1 & 1250 & 66 & 1 & 22 & 45 & $* *$ \\
\hline Md Rouf & 8.5 & 8.5 & 96000 & 325 & 0 & 00 & 330 & $* * *$ \\
\hline $\begin{array}{l}\text { Abdul } \\
\text { Khalek }\end{array}$ & 1 & 1 & 1200 & 54 & 1 & 22 & 30 & $*$ \\
\hline
\end{tabular}




\begin{tabular}{|c|c|c|c|c|c|c|c|c|}
\hline $\begin{array}{c}\text { Md } \\
\text { Alamin } \\
\text { Hossain }\end{array}$ & 0.66 & 0.66 & 700 & 32 & 0 & 00 & 32 & $*$ \\
\hline $\begin{array}{c}\text { Md } \\
\text { Johurul } \\
\text { Islam }\end{array}$ & 0.5 & 0.5 & 600 & 29 & 1 & 22 & 20 & $*$ \\
\hline $\begin{array}{c}\text { SM } \\
\text { Khalilur } \\
\text { Rahman } \\
\text { Khalil }\end{array}$ & 1 & 0.75 & 900 & 55 & 1 & 11 & 54 & $* * *$ \\
\hline $\begin{array}{c}\text { Md } \\
\text { Monsur } \\
\text { Ali }\end{array}$ & 2.5 & 1.5 & 2000 & 72 & 1 & 11 & 74 & $* * *$ \\
\hline $\begin{array}{c}\text { Mohamma } \\
\text { d } \\
\text { Azgar }\end{array}$ & 0.75 & 0.50 & 600 & 33 & 1 & 22 & 30 & $* *$ \\
\hline $\begin{array}{c}\text { Al } \\
\text { Kawshar } \\
\text { Ahmed }\end{array}$ & 3 & 0.66 & 700 & 32 & 1 & 32 & 33 & $* *$ \\
\hline
\end{tabular}

\section{G. Result Analysis with data Weka}

Performance parameters are the most important factor to compare among classifier methods to get the best classifier. Applied performance metrics includes Accuracy, Sensitivity, Specificity, precision, Recall, F-measure, Matthew's Correlation Coefficient (MCC), Receiver Operating Characteristic (ROC) Area, and Precision Recall Curves (PRC). These parameters calculated from a confusion matrix which situated in every step of classification. About confusion matrix and detailed information about these proposed parameters are as follows:

TP represents the number of correctly classified positive instances.

FP represents the number of misclassified positive instances.

FN represents the number of misclassified negative instances.

TN represents the number of correctly classified negative instances.

$$
\begin{aligned}
& \text { Accuracy }=\frac{T P+T N}{T P+T N+F P+F N} \\
& \text { Specificity }=\frac{T N}{T N+F P} \\
& \text { Sensitivity }=\frac{T P}{T P+F N} \\
& \text { Precision }=\frac{T P}{T P+F P} \\
& \text { Recall }=\frac{T P}{T P+F N} \\
& \text { F-measure }=\frac{2 * \text { precision } * \text { recall }}{\text { precision }+ \text { recall }}
\end{aligned}
$$

We got several accuracy level using different classification option and different methods. We also used cross-validation in our dataset to validate our training set properly. Performance of each of the classifiers used is portrayed graphically in Fig 4.

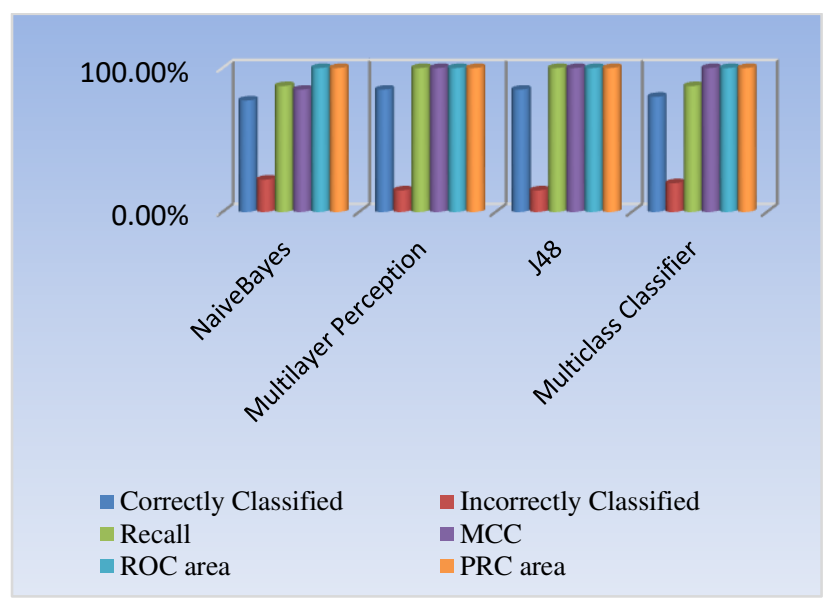

Fig 4: Detailed Accuracy for 10 fold cross validation and percentage split $80 \%$ for rice (Rajshahi).

\section{G. Projecting the summary through android app}

We created an android based application to depict the summarized result. It contains detailed information related to the study. Some screenshots of the application is stated below Fig 5.

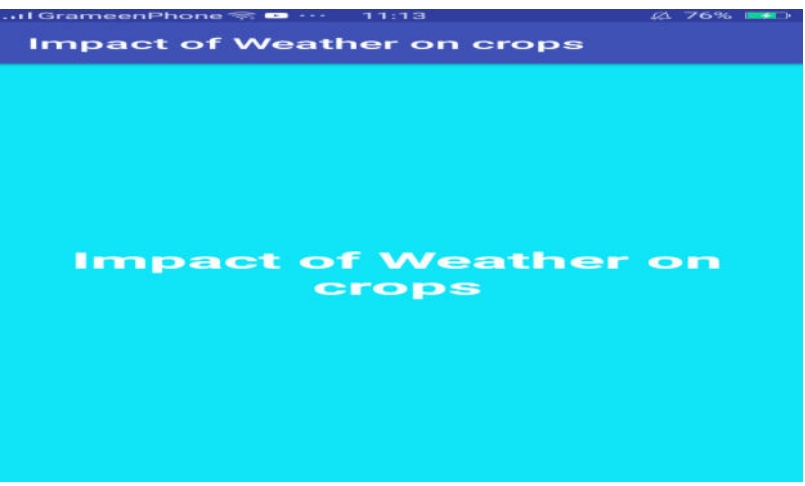

Fig 5: Splash Page.

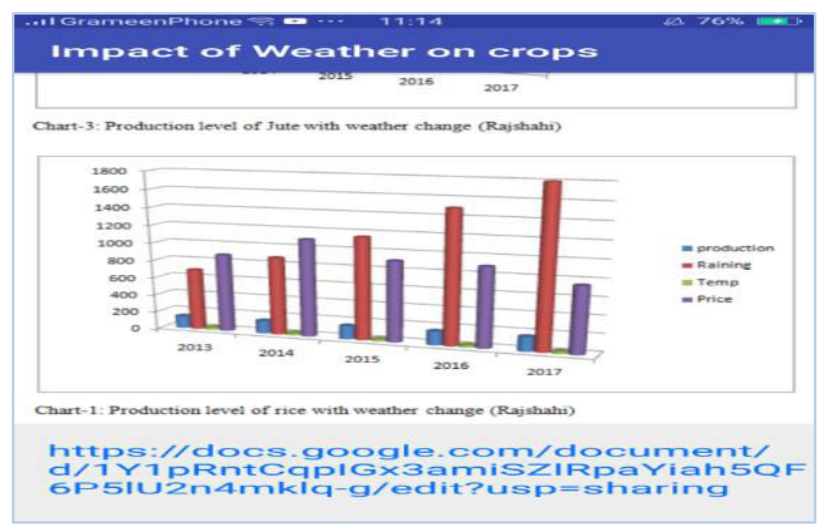

Fig 6: page with Google drive link and graphically view. 


\section{CONCLUSION AND FUTURE WORK:}

This paper contributes to HCI by expanding the impact of weather on crops in case of Bangladesh (Rajshahi and Pabna). We have explained the problems and experience of farmers. We have also pointed out suggestions of officers of different sectors. Though, the implemented model will be helpful to calculate the accurate percentage of production of various crops with the change of weather, we needed large number of data for implementing the model. But, as most of the farmers are not literate enough, they could not reply properly to our questionnaire. So, we had to discard some of the data as they were not adequate. This was the main limitation of our work. In future we want to build an artificial intelligence based interactive application collecting more data, that will be beneficial to the agricultural sector of those region and would be handful for the farmers for good growth of appropriate crops based on weather.

\section{ACKNOWLEDGEMENT:}

Many thanks to the co-author supported with proper assistance and help for analysis and writing to conduct successful research study.

\section{CONFLICTS OF INTEREST:}

The authors declare they have no competing interests with respect to the research.

\section{REFERENCES:}

1) Akter S, Kamal TB, Khatun M, Alam MM, Hossen MZ, and Karim R. (2020). Influence of potential differential voltage on electric resistance of needle punched non-woven jute fabrics, Aust. J. Eng. Innov. Technol., 2(1), 1-6. https://doi.org/10.34104/ajeit.020.0106

2) Alex C. Ruane, David. C. M., Winston H.Yu., Mozaharul A. (2013). Multi-factor impact analysis of agrcultural production in Bangladesh with climate change. Global environmental change, 23(1): 338-350. https://doi.org/10.1016/j.gloenvcha.2012.09.001

3) Andrew Faulring, Brad Yaad O., Keren R. (2012). A case study of using HCI methods to improve tools for programmers. A. M., pp. 37-39. https://doi.org/10.1109/CHASE.2012.6223018

4) Anita Mirjamdotter, Mary M. Somerville. (2009). Collaborative design: An SSM- enabled organizational learning approach. Information Technologies and Systems Approach, 2(1): 48-69. https://doi.org/10.4018/jitsa.2009010104

5) Bagchi R, Miah MA, Islam MA, Bithi SA, and Shamsuzzoha M. (2019). Assessment on climate change adaptation: a study on coastal area of Khulna district in Bangladesh, Aust. J. Eng. Innov. Technol., 1(6), 14-20. https://doi.org/10.34104/ajeit.019.14020

6) Corey Lesk, Pedram R. \& Navin R. (2016). Influence of extreme weather disasters on global crop production. Nature, 529: 84-87. https://doi.org/10.1038/nature16467

7) Deepak K. Ray, Ramankutty N, Mueller ND, West PC, Foley JA. (2012). Recent patterns of crop yield growth and stagnation. Nat Commun. 3:1293. https://doi.org/10.1038/ncomms2296

8) Dix A. Finlay J. E. , Abowd G.D, Beale R. (2003). Human-Computer Interaction, Third edition. Harlow: Pearson Education. ISBN13: 978-0130461094.

9) Fraser A. J., Ewert F, Arnold S., Simelton E., Fraser E. (2009). Crops and climate change: progress, trends, and challenges in simulating impacts and informing adaptation. Journal of Experimental Botany,60(10): 2775-2789. https://doi.org/10.1093/jxb/erp062

10) Ghimire, TB., and Thakur NS. (2013). Constraint and opportunity of raw jute production : A case study of eastern Terai, Nepal. Agronomy J. of Nepal. 3: 117-122. https://doi.org/10.3126/ajn.v3i0.9013

11) Hall M., Frank E., Holmes G. (2009). The WEKA data mining software: an update. ACM SIGKDD Explorations Newsletter, 11(1):10-18.

12) Islam KA, Deeba $F$, and Hassan MKA. (2019). Dust ion acoustic solitary waves in multi-ion dusty plasma system with adiabatic thermal change, Aust. J. Eng. Innov. Technol., 1(5), 1-5. https://doi.org/10.34104/ajeit.019.0105

13) Islam MA, Sumy MSA, Uddin MA, and Hossain MS. (2020). Fitting ARIMA model and forecasting for the tea production, and internal consumption of tea (per year) and export of tea, Int. J. Mat. Math. Sci., 2(1), 815. https://doi.org/10.34104/ijmms.020.08015 
14) Islam MT and Hossain MS. (2019). Hybridization of vigenere technique with the collaboration of RSA for secure communication, Aust. J. Eng. Innov. Technol., 1(6), 6-13.

https://doi.org/10.34104/ajeit.019.06013

15) Jayanta Kumar Basak, Rashed Al Mahmud Titumir and Nepal Chandra Dey (2013). Climate Change in Bangladesh: A Historical Analysis of Temperature and Rainfall Data. Journal of Environment, 2(2) 41-46 .

16) MA Hossain, M. Shoeb Hassana , M. Abdul Mottalib (2015). Feasibility of solar pump for sustainable irrigation in Bangladesh. International journal of Energy and Environmental Engineering, 105: 147-155.

17) Md Torikul Islam, and Melissa Nursey-Bray (2017). Adaptation to climate change in agriculture in Bangladesh: the role of formal institutions. Enironmental Management, 200: 347-358. https://doi.org/10.1016/j.jenvman.2017.05.092

18) Md. Ruhul Amin, Junbiao Zhang, and Mingmei Yang (2015). Effects of Climate Change on the Yield and Cropping Area of Major Food Crops: A Case of Bangladesh. Sustainability, 7: 898-915. https://doi.org/10.3390/su7010898

19) Pereda P., \& Alves D. (2018). Climate and Weather Impacts on Agriculture: The Case of Brazil. Economia Aplicada, pp. 1-28.

20) Rish, I. (2001). An empirical study of the naive Bayes classifier. IJCAI workshop on empirical methods in artificial intelligence, 3(22), 41-46. https://doi.org/10.1371/journal.pone.0102366

21) Ruksana Haque Rimi, Syed Hafizur Rahman, Sk. Ghulam Hussain (2009). Trend Analysis of Climate Change and Investigation on Its Probable Impacts on Rice Production at Satkhira, Bangladesh. Pakistan J. of Meteorology, 6(11), 37-50.

22) Russell S., Norvig P. (2002). Artificial intelligence: a modern approach. ISBN13: 978-0136042594.

23) Sanzidur Rahman, M. Kamrul Hasan. (2008). Impact of the environmental production condition on productivity and efficiency, a case of wheat farmers of Bangladesh. Environmental Management, 88 (4), 1495-1504.

http://dx.doi.org/10.1016/j.jenvman.2007.07.019

24) Shahin, S. (2011). Impact of climate change on irigation water demand of dry season Boro rice in northwest Bangladesh. Climatic Change, 105: 433-453. https://doi.org/10.1007/s10584-010-9895-5

25) Shamsuddin Shahid, X. C. M. K. H. (2006). Evaluation of groundwater quality for irrigation in Bangladesh using geographic information system. Hydrology and Hydromechanics, pp. 3-14.

26) Syed Ishtiaque Ahmed, Nusrat Jahan Mim , Steven J Jackson (2015). Residual Mobilities: Infrastructural Displacement and Post-Colonial Computing in Bangladesh. CHI 2015, Crossings, Seoul, Korea, p. 437 446. https://doi.org/10.1145/2702123.2702573

Citation: Ahmed MT, Imtiaz MN, and Mitu NS. (2020). Impact of weather on crops in few northern parts of Bangladesh: HCI and machine learning based approach, Aust. J. Eng. Innov. Technol., 2(1), 7-15. https://doi.org/10.34104/ajeit.020.07015 C) $\underset{\mathrm{EY}}{\mathrm{C}}$ 